\title{
8
}
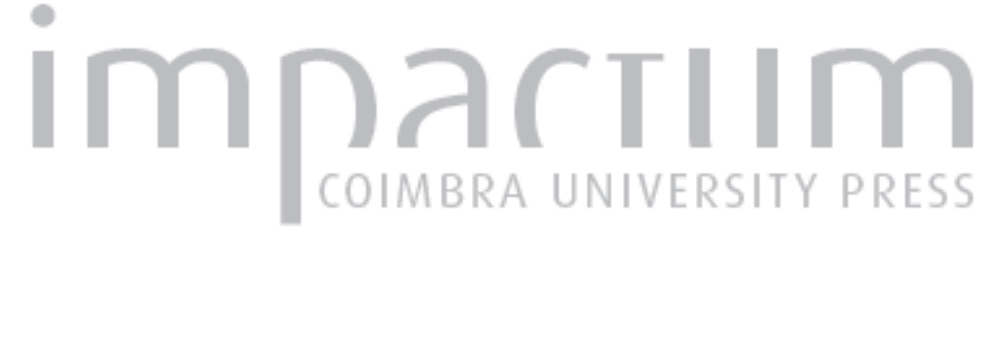

Violência(s) e guerra(s): do triángulo ao continuum
Autor(es):
Pureza, José Manuel; Moura, Tatiana
Publicado por: Instituto de História Económica e Social; Imprensa da Universidade de Coimbra

URL

persistente:

URI:http://hdl.handle.net/10316.2/44495

DOI:

DOI:https://doi.org/10.14195/0870-4147_37_3

Accessed : $\quad$ 26-Apr-2023 12:40:32

A navegação consulta e descarregamento dos títulos inseridos nas Bibliotecas Digitais UC Digitalis, UC Pombalina e UC Impactum, pressupõem a aceitação plena e sem reservas dos Termos e Condições de Uso destas Bibliotecas Digitais, disponíveis em https://digitalis.uc.pt/pt-pt/termos.

Conforme exposto nos referidos Termos e Condições de Uso, o descarregamento de títulos de acesso restrito requer uma licença válida de autorização devendo o utilizador aceder ao(s) documento(s) a partir de um endereço de IP da instituição detentora da supramencionada licença.

Ao utilizador é apenas permitido o descarregamento para uso pessoal, pelo que o emprego do(s) título(s) descarregado(s) para outro fim, designadamente comercial, carece de autorização do respetivo autor ou editor da obra.

Na medida em que todas as obras da UC Digitalis se encontram protegidas pelo Código do Direito de Autor e Direitos Conexos e demais legislação aplicável, toda a cópia, parcial ou total, deste documento, nos casos em que é legalmente admitida, deverá conter ou fazer-se acompanhar por este aviso.

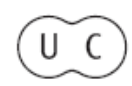




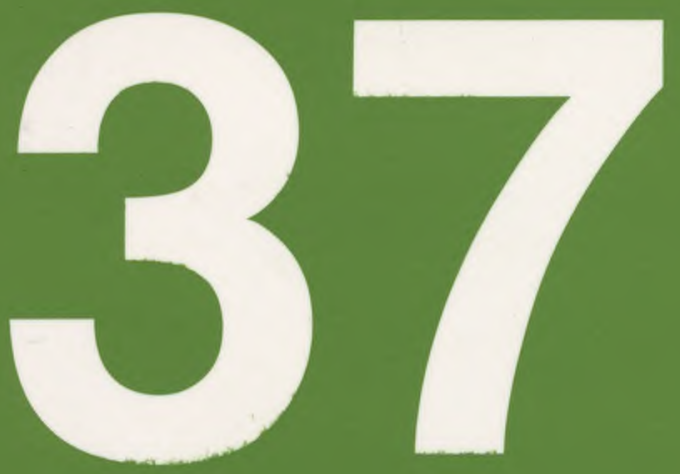

Revista Portuguesa de História

Faculdade de Letras da Universidade de Coimbra Instituto de Historia Econónica e Samial

Coimbra 05 


\section{Violência(s) e Guerra(s): Do Triángulo ao Continuum}

JosÉ MANUEL PUREZA

TATIANA MOURA

Núcleo de Estudos para a Paz, Centro de Estudos Sociais

Faculdade de Economia da Universidade de Coimbra

"Os estudos da violencia, parte indispensável dos estudos para a paz, podem ser urna cámara de horrores; mas, tal como a patologia, reflectem uma realidade que tem que ser conhecida e compreendida". O mesmo autor desta afirmação, Johan Galtung, vulto de primeira grandeza na área dos peace studies, advertiu desde cedo (1969:168) que não é particularmente importante atingir $a$ definição ou a tipología da violência. "Muito mais importante, escreveu ele, é indicar dimensões teóricas significativas da violência que possam orientar o pensamento, a investigação e, potencialmente, a acção para os problemas mais importantes. (...) [o] conceito de violência deve ser suficientemente amplo para incluir as variantes mais destacadas e suficientemente específico para servir de suporte à acção concreta".

Neste texto, ensaiamos uma aproximação a essas dimensões teóricas significativas, retomando a construção tripartida de Galtung: violência física, estrutural e cultural, como recordamos na primeira parte. A guerra tem sido percebida e teorizada como uma expressão de escala ampla da violência física. Na segunda parte deste artigo, procuraremos, a partir de um registo da trajectória conceptual da guerra, re-situá-la como síntese de alta intensidade da violência física, da violência estrutural e da violência cultural. 


\section{Violências}

A peace research acolheu como matriz fundadora uma visão ampla e multidimensional da violência. Distinguindo claramente conflito e violência a violência pode ser uma das condutas dos actores envolvidos no conflito ou a expressão de que a transformação do conflito em oportunidade de soma positiva fracassou - Galtung sugeriu, logo nos textos iniciais daquela corrente de investigação-acção, uma noção ampla e normativa de violência:

"A violência existe sempre que se influenciam seres humanos de modo a que as suas realizações somáticas e mentais fiquem aquém das suas potenciais realizações" (1969: 168)

Esta noção de partida afasta-se efectivamente de uma concepção restrita, de acordo com a qual a violência é "somente uma incapacitação somática ou uma privação da saúde (com o assassinato como forma extrema), às mãos de um actor que pretende que essas sejam as consequências" do seu comportamento. Uma tal concepção restrita tomaria a paz, enquanto negação da violência, compatível com ordens sociais com contornos inaceitáveis (ibidem: 168).

Numa elaboração posterior ( 1990:292), Galtung redefiniu a violência como “ofensas evitáveis às necessidades humanas básicas e à vida em geral, reduzindo os níveis de satisfação dessas necessidades abaixo do que é potencialmente possível". Com uma outra fórmula e uma nova centragem, mantém-se a amplitude e a natureza normativa da definição.

Sobre esta perspectiva multidimensional, Galtung opera seis distinções/ /dicotomias. A primeira é entre a violência física e a violência psicológica; a segunda é entre o uso de meios negativos ou positivos de influência; a terceira é entre violência com um objecto determinado e sem objecto; a quarta é entre violência com um sujeito identificado e violência sem sujeito; a quinta é entre violência intencional e violência não intencional; e a sexta é entre violência manifesta e violência latente. Destaca-se, entre estas distinções, a que decorre da identificação do sujeito da violência. Aí Galtung faz assentar a diferença entre violência pessoal e violência estrutural, relacionando esta última com a injustiça social e caracterizando-a como tendencialmente latente (1969: 172). E nesta distinção matricial a escola da peace research perspectivou um autêntico corte epistemológico: "a tradição tem sido pensar a violência apenas como violência pessoal (...). Aqui a opção consiste em fazer da distinção entre violência pessoal e estrutural a fundamental" (ibidem: 173).

A recondução destas duas dimensões - pessoal e estrutural - a uma mesma realidade (violência) é simultaneamente estratégica e ideológica. Estratégica 
porque supõe a decisão de não ignorar nenhuma delas na compreensão da outra. Em bom rigor, esta dimensão estratégica do conceito de violência é ela própria ideológica: de modo implícito, veicula-se nesta unidade conceptual a tese de que a violência estrutural é uma das causas principais da violência física. Mas há um lado assumidamente ideológico nesta concepção ampla e unitária da violência: "tendo a violência estrutural e a violência pessoal consequências sociais negativas, tentar reduzir os níveis da segunda sem incluir a primeira não permite ter a certeza de uma melhoria final da situação" (Derriennic, 1972: 361).

Deve notar-se que quer a amplitude de formulação do conceito de violência em Galtung quer as dimensões/dicotomias que ele identificou nesse conceito suscitaram viva polémica ao longo de duas décadas. A primeira nota crítica prende-se com o fosso entre, de um lado, a acepção normativa e unitária do conceito de violência, fundada na distância entre o potencial (o que poderia ter sido) e o real (o que é) e, do outro, o senso comum sobre a violência nos diferentes registos culturais. A segunda nota crítica diz respeito a uma alegada equivocidade dos contornos das dimensões ou formas de violência incluídas naquela concepção ampla. Para alguns dos críticos, a noção de violência estrutural envolveria uma confusão de base entre violência exercida por uma estrutura e violência exercida através de uma estrutura. Por seu tumo, a noção de violência pessoal seria também desfocada ao comportar em simultâneo as acções individuais e as acções de grandes colectivos. Daí a sugestão de referências mais nítidas, em especial de violência organizada e violência não organizada e de violência directa e violência indirecta. Como adverte Derriennic (1972:362), não se trataria, aliás, de dicotomias mas antes de dimensões contínuas já que a violência pode ser mais ou menos directa e pode ser mais ou menos organizada.

Em 1990, Galtung introduziu uma nova forma ou dimensão de violência: a violência cultural. Define-a como qualquer aspecto ou elemento de uma cultura, da esfera simbólica da nossa existência - por exemplo, a religião e a ideologia, a liguagem e a arte, a ciência empírica e a ciência formal (lógica e matemática) - que pode ser usado para legitimar socialmente a violência directa ou estrutural. A violência cultural, actuando através de mecanismos de interiorização, faz com que a violência directa e estrutural pareçam correctas, ou que pelo menos não pareçam erradas (1990: 261).

"A violência directa é um facto, a violência estrutural é um processo e a violência cultural é uma invariância, uma permanência (...). Usando a terminologia da escola dos Annales, a violência directa é événementielle, a violência estrutural é conjoncturelle e a violência cultural pertence ao domínio da longue durée. Esse relacionamento diferenciado das três dimensões da violência com o tempo deu origem a um conhecido paralelismo com a teoria sísmica: o abalo sísmico 
como um facto, o movimento das placas tectónicas como um processo e a falha como uma condição permanente (1990: 294).

Galtung relaciona os três tipos de violência (directa, estrutural e cultural) naquilo a que chama o triângulo da violência (1990: 294). Esta imagem geométrica é preferida a uma representação geológica igualmente sugerida por Galtung (1990:294). Tratar-se-ia da imagem dos estratos da violência. O estrato mais profundo seria o da violência cultural, "substrato de que os outros dois podem retirar os seus nutrientes." No estrato intermédio localizam-se os ingredientes da violência estrutural (a exploração, os mecanismos de segmentação que impedem a consciencialização e os mecanismos de fragmentação e de maiginalização que impedem o desenvolvimento de organização contra a exploração e a repressão). Finalmente, o estrato mais superficial seria o da violência directa. No entanto, a sugestão de uma relação causal de sentido único que esta imagem poderia acarretar levou Galtung a afastá-la em favor da do triângulo da violência. Embora identifique fluxos de causalidade em todas as direcções do triângulo "quando o triângulo tem como base a violência directa e a violência estrutural a imagem invocada é a da violência cultural como legitimadora de ambas. Quando tem como vértice superior a violência directa, a imagem é a da violência cultural e da violência estrutural como fontes da violência directa" (ibidem: 294) - Galtung identifica um fluxo causal primeiro que parte da violência cultural, passando pela estrutural e se materializa na directa (ibidem: 295). Isto é, a cultura faz com que vejamos a exploração e/ou a repressão como normais ou naturais, ou que simplesmente não as vejamos. E a manutenção ou quebra dessa violência estrutural passa pelo recurso à violência directa. O "síndroma triangular" passa pela institucionalização de estruturas violentas, intemalização de uma cultura violenta e consequente institucionalização e repetição da violência directa: "com a estrutura violenta institucionalizada e a cultura violenta interiorizada, a violência directa também tende a tomar-se institucionalizada, repetitiva, ritualizada, como uma vendetta" (ibidem: 302).

Segundo Tortosa (v. fig. 1 ), e na mesma linha de análise de Galtung, estamos perante três fenómenos diferentes mas que estão interrelacionados: por um lado, o comportamento violento; por outro, os conflitos e contradições dos quais resulta esse comportamento; e, por último, o conjunto de racionalizações, legitimações e mesmo incitamentos tanto ao comportamento violento como ao conflito ou à injustiça (2003: 65-66). 
Figura 1

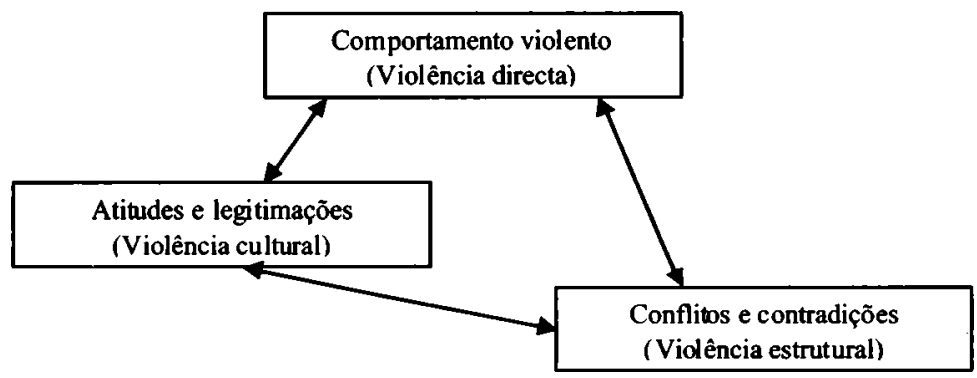

Fonte: Tortosa, 2003: 66

Desta visão tripartida se aproxima igualmente a proposta de desenho do mapa dos conflitos e da sua formação, avançada por Romeva (actores/condutas/ /incompatibilidades). Os actores que exercem condutas violentas (violência directa, visível) justificam a sua acção baseando-se na percepção de incompatibilidades e injustiças de ordem estrutural (violência estrutural, visível ou pouco visível), que por sua vez serve para legitimar essa forma de actuar como a única possível (violência cultural, menos visível ou invisível). A violência directa reforça assim a violência cultural e estrutural (e frequentemente o domínio de quem exerce estas últimas) e pode resultar numa guerra (Romeva, 2003: 35).

\section{A guerra como expressão radical das violências}

O senso comum e o conhecimento académico tradicionais identificam a guerra com a violência física em larga escala e perpetrada de modo organizado ou com a ameaça de a usar. Os clássicos da polemologia tiveram o condão de postular de modo claro essa relação conceptual entre a guerra e a violência. Assim, Clausewitz definiu o conceito na sua obra Da Guerra (1832) como "acto de violência que tem como objectivo obrigar o adversário a executar a nossa vontade", e como "a continuação da política por outros meios". Quincy Wright ( 1942), por seu turno, vê na guerra "um conflito entre grupos políticos, especialmente entre Estados soberanos, conduzidos por importantes contingentes de forças armadas durante um período de tempo considerável". Gaston Bouthoul (1976) defende que a guerra corresponde a uma forma de violência que tem como característica essencial ser metódica e organizada no que se refere aos grupos que a praticam e à forma como a levam a cabo; para além disso é limitada no tempo e no espaço e submetida a regras jurídicas particulares extremamente variáveis segundo os lugares e as épocas. 
A esta tentativa de clarificação conceptual vão associadas padronizações baseadas em indicadores quantitativos. Assim, enquanto para Dan Smith (2001 : 4) a guerra supõe a verificação de "pelo menos 25 mortes no espaço de um ano, no contexto de um número total de mortes relacionadas com o conflito de pelo menos várias centenas", para Wallensteen e Sollenberg (2001: 631-633) há lugar a uma distinção entre conflitos armados menores, intermédios e guerra em função do número de baixas: um conflito é menor quando o número de mortes resultantes dos confrontos durante o período do conflito é inferior a 1000; é intermédio quando se registam mais de 1000 mortes como consequência do conflito, mas menos de 1000 no período de um ano; e estamos perante uma guerra quando se registam mais de mil mortes num ano.

Esta identificação entre guerra e violência física directa e organizada, que remete as violências estrutural e cultural para a periferia - ou mesmo para o exterior - da prática concreta da guerra deve ser questionada. A evolução da própria configuração da guerra, registada em abundante literatura desde a década de noventa do século XX, pode ser lida como convocando a uma releitura que traga de modo mais explícito a violência estrutural e a violência cultural para o centro do conceito mesmo de guerra. Não o fazer equivale a invisibilizar o continuum entre violência directa, violência estrutural e violência cultural. Mais: equivale a isolar a violência física das suas causas estruturais e culturais. É claro que, como já se disse atrás, a violência estrutural e a violência cultural são de ciclo longo, silenciosas. Mas isso de modo nenhum legitima que se acrescente a esse silêncio um outro, deliberado, de ocultação do que está na base das várias formas de violência directa, das várias guerras ou de práticas violentas.

É certo que estas violências mudam e se adaptam. O itinerário que a seguir propomos pretende ilustrar essa dinâmica de reconfiguração. Mas, a par desta mudança de tipologías da guerra, há uma permanência: o patriarcado, entendido como verdadeiro sistema de guerra, baseado na construção e perpetuação de masculinidades dominantes, subjaz a todas as práticas concretas de guerra. É parte central da violência cultural; dita a exclusão na violência estrutural; e manifesta-se de forma visível nas praticas de violência directa.

\subsection{A velha guerra moderna}

A construção de Estados modernos pressupôs a criação de monopólios públicos de violência(s), que Norbert Elias designou como "processo civilizatório" e que constituiu um elemento fundamental daquilo a que Benedict Anderson chamou "comunidades imaginadas": retirar um determinado tipo de violência da vida quotidiana dentro das fronteiras de um Estado, estabelecendo um equilíbrio 
entre o interesse do governante (privado) e o interesse dos membros da sociedade regulada pelo Estado (público), estabelecendo as fronteiras entre esfera pública e privada, militar e civil, económica e política, etc. A construção de monopólios públicos - da violência e dos meios económicos que permitiam a manutenção do monopólio da violência - esteve intimamente ligada às guerras contra outros Estados, que passou a ser considerada a única forma legítima de violência otganizada.

A guerra moldou-se, pois, à mundividência da modernidade. Institucionalizando-se e profissionalizando-se, primeiro. E tomando-se total, depois (Holsti, 1996).

A raison d 'état, os conflitos dinásticos e a consolidação de fronteiras animaram a criação de exércitos, estruturas verticais, organizadas e hierarquizadas inicialmente compostas por mercenários e, mais tarde, numa tentativa de garantir a lealdade ao monarca, transformadas em exércitos fixos e profissionais, identificados com uniformes e sujeitos a treinos militares regulares, que os mantinham ocupados em períodos de paz. A criação de exércitos sob o controlo estatal constituiu, pois, a pedra de toque da monopolização legítima da violência intrínseca ao Estado moderno (Kaldor, 2001: 16-17). A guerra surgia, assim, segundo a máxima de Clausewitz, como "a continuação da política por outro meios".

A guerra emergia num contexto de novas distinções (distinções binárias ou dicotomias) características do Estado moderno: a distinção entre o público e o privado, entre a esfera da actividade estatal e a actividade não estatal; a distinção entre a esfera intema e a externa, entre o nível nacional e o internacional; a distinção entre o económico e o político; a distinção entre a esfera civil e a esfera militar, entre a intervenção intra-fronteiras não violenta e a intervenção extema violenta. Ou seja, surgia a principal dicotomia, em tomo da qual todas as outras assentam: a distinção entre guerra e paz (Kaldor, 2001: 20).

Profissionalizada e institucionalizada, a guerra tomou-se total na viragem para o século XX. Desde logo pelo impacto da industrialização, traduzido num aumento exponencial da capacidade destrutiva das máquinas de guerra, animadas pela produção em massa de armamento e pela abertura de novos patamares bélicos (a guerra aérea e a guerra submarina, por exemplo). Mas total, sobretudo, pela democratização do seu imaginário, tomada possível pelas revoluções comunicacionais e pela consequente mediatização e democratização da até então socialmente selectiva high politics. Não é indiferente a esta trajectória a progressiva amplificação ideológica dos fundamentos do recurso à guerra que, muito grosseiramente, simplificaremos no trânsito do nacionalismo tout court para a "luta contra o mal" (nesse sentido, a Guerra Fria foi a guerra total por excelência).

Vale a pena realçar que este processo evolutivo da guerra moderna se encarregou de iniciar a diluição das dicotomias em que assentou a sua construção... 
moderna. Com efeito, a massificação dos exércitos, a mobilização social total, as economias nacionais de guerra e a disseminação dos efeitos letais da guerra - na I Guerra Mundial os alvos militares considerados legítimos eram os alvos económicos; na II Guerra Mundial, o genocídio e o bombardeamento indiscriminado de civis foram justificados como necessidade militar - determinaram, em conjunto, um apagamento das fronteiras herméticas entre o civil e o militar, entre o político e o económico e mesmo entre o público e o privado. Talvez mesmo entre a guerra e a paz.

Deste ponto de vista, as três grandes guerras do século XX recolocaram de modo progressivamente mais claro a questão das violências potenciadas pela guerra. É óbvio que as duas guerras mundiais levaram a violência física organizada a patamares inéditos. Mas não pode ignorar-se a importância histórica e cognitiva da denúncia, reiterada pelo movimento pacifista, da íntima articulação entre a guerra e a institucionalização, em escala nacional e internacional, de mecanismos de violência estrutural. A Guerra Fria - e as resistências pacifistas de um lado e do outro - vincaram bem que a visão da guerra confinada à violência física é superficial, captando o epifenómeno chocante e ignorando as suas raízes mais fundas.

\subsection{Novas guerras pré-modernas?}

O final da Guerra Fria marcou uma viragem na visão académica e de senso comum sobre a guerra. Essa viragem prolongou, neste terreno, a grande centralidade analítica conferida ao conceito de Estados falhados ou colapsados (Zartman, 1995; NEP, 2002; Rotberg, 2003). Essa viragem assenta no acolhimento muito alargado duma dupla hipótese. Por um lado, à centralidade da guerra na modernidade teria sucedido, como parte integrante da narrativa do fim da História, uma marcada tendência para a "não guerra entre Estados" (David, 2001: 118) ou para a desbelicização (Mandelbaum, 1999). Por outro lado, a guerra teria passado a ser a nova (?) condição estrutural da periferia do sistema mundial, das borderlands (Duffield, 2001) afogadas no caos económico e social e na violência hobbesiana. E, nesse contexto, a guerra como constante exprimiria a persistência de uma espécie de selvajaria primordial. É a modernidade arcaica (Herrmann e Palmieri, 2003) que se manifesta na viragem para o século presente.

É nesse contexto que surge o conceito de novas guerras - com actores, condutas e interesses antagónicos que não encaixam nas anteriores definições e análises dos conflitos bélicos. Daí a grande dificuldade na sua adjectivação: guerra "pré-moderna" (Van Creveld, 1991), guerra "do terceiro tipo" (Holsti, 1996) ou guerra “capilarizada” (Bigo, 1996). 
Mary Kaldor (2001) foi pioneira na definição e análise deste novo tipo de conflitos violentos, defendendo que estas novas guerras correspondem a um novo tipo de violência organizada que é diferente porque faz com que não se vejam as diferenças entre guerra, crime organizado (violência conduzida por grupos de organização privada, com objectivos privados, normalmente o lucro financeiro) e violações em larga escala de direitos humanos (geralmente por parte de Estados ou por grupos politicamente organizados contra indivíduos). Contrariando o entendimento que moldou os debates do pós-Guerra Fria sobre o carácter da nova conflitualidade, Kaldor defende que as guerras dos anos 90 não são apenas "guerras civis" produzidas por "conflitos étnicos", ou que temos vindo a assistir a uma mera privatização da violência. De facto, nestas novas guerras não é fácil de estabelecer na prática a distinção entre o privado e o público, o estatal e o não estatal, o informal e o formal, o que se faz por motivos económicos ou políticos.

As novas guerras contrastam com as guerras consideradas tradicionais em termos dos seus actores (agentes e vítimas da violência), métodos de guerra (condutas), objectivos (interesses antagónicos) e o modo de financiamento (Kaldor, 2001: 6; Ghebali, 2001). As velhas guerras tinham como principais actores ou agentes da violência os Estados e os exércitos - unidades hierárquicas verticalmente organizadas. Os seus objectivos eram ideológicos e geopolíticos. Os métodos de guerra utilizados passavam pela captura de território através de meios militares, ou seja, a esfera pública era o cenário da violência - as batalhas constituíam os encontros decisivos das velhas guerras. A economia de guerra, em particular na I e II Guerra Mundial, era uma economia de mobilização, centralizada e totalizadora. Nas novas guerras os principais actores ou protagonistas da violência dificilmente se distinguem da população civil, e envolvem uma enorme diversidade de grupos - unidades paramilitares (que incluem frequentemente crianças), senhores da guerra locais, faç̧ões criminosas, grupos de mercenários, forças da polícia, mas também exércitos regulares, incluindo unidades dissidentes de exércitos regulares (Kaldor, 2001). Estas unidades de combate caracterizam-se pelo uso alargado de armas ligeiras (que são mais fáceis de transportar, mais precisas e podem ser utilizadas por soldados sem formação especial), pelo recurso a novas tecnologias (como telemóveis e internet), recorrem a novos métodos para obtenção de controlo político, criação e manutenção de um clima de ódio, medo e insegurança. As novas guerras podem ser vistas como uma forma de aproveitamento, material e humano, do que "sobrou" da Guerra Fria - em particular das armas acumuladas ao longo de décadas e oferecendo uma alternativa económica (ainda que muitas vezes ilegal) a antigos soldados e combatentes de exércitos tradicionais. 
A sociedade civil é simultaneamente o palco e o alvo da violência organizada, que ocorre na esfera privada, privatizando a violência, os seus espaços ou territórios de actuação, os seus actores e as suas vítimas. Ou seja, a população civil assume o papel de actor mas é também alvo de uma conduta ou estratégia utilizada para alcançar um objectivo, nestas novas guerras. São portanto guerras declaradas contra a dimensão privada das sociedades, silenciando a morte de milhares de pessoas. Apesar de penalizadas ética e juridicamente, as atrocidades deliberadas contra a população não combatente ou a destruição de monumentos históricos não só persistem como adquirem um alcance mais intensamente deliberado nas novas guerras. Ou seja, o que era considerado como efeito secundário indesejável e ilegítimo das velhas guerras tomou-se um elemento essencial na forma de luta ou de conduta dos actores das novas guerras, recusando limites normativos (Kaldor, 2001).

As guerras com legitimação ideológica foram substituídas por guerras por recursos, e a violência deixou de ser uma excepção, ou um acontecimento temporário, para se tomar num elemento importante da sobrevivência política e económica em lugares que carecem de alternativas. Para Duffield, a característica mais marcante destas novas guerras é o desenvolvimento de economias políticas de guerra ou de sistemas de financiamento (1994: 57) que se baseiam na exploração e exportação de recursos naturais, cultivo e exportação de drogas, tráfico de armas, etc., que se reproduzem num sistema de renovação da violência. Estas actividades económicas ilegais não são um processo anárquico, fazem parte de uma ampla economia paralela de âmbito local, nacional, regional e internacional, permitindo que o conflito se prolongue e se auto-alimente.

Esta nova economia de guerra - economia de guerra globalizada ou nova economia política da guerra - é praticamente o oposto das economias de guerra que possibilitaram a I e a II Guerras Mundiais. Perante os elevados índices de desemprego e de desigualdades sociais, a diminuição da produção interna e das receitas provenientes dos impostos, e da destruição física típicos destes contextos, estas economias de guerra são altamente descentralizadas e dependentes de recursos extemos (especialmente de remessas do estrangeiro, como as provenientes das diásporas, da própria assistência humanitária e das redes de comércio ilegal). A violência depende destas fontes de financiamento para se manter e perpetuar e, por sua vez, esta economia só se mantém através de um continuum de violência que atravessa fronteiras. A nova economia de guerra globalizada corresponde, em síntese, a uma condição social predatória, que apesar de ser mais comum em zonas de conflito afecta as economias de regiões envolventes. É possível, portanto, identificar pólos activos ou passivos de economias de guerra em muitas regiões do mundo (Kaldor, 2001: 9), dificultando a distinção entre zonas de guerra e zonas de paz. 
Kalyvas (2001) analisa esta linha de argumentação que pretende distinguir entre "velhas guerras civis" e "novas guerras civis" do pós-Guerra Fria e critica a leitura dicotómica que ela sustenta. A maioria das distinções entre velhas e novas guerras civis defende que as "[...] novas guerras civis têm características criminosas, são despolitizadas, privadas e predatórias, enquanto que as velhas guerras civis são consideradas ideológicas, políticas, colectivas e mesmo nobres" (Kalyvas, 2001:100). Esta distinção toma como fundamento a suposta racionalidade das velhas guerras por oposição a uma suposta irracionalidade cega das novas guerras, seja em termos de motivações seja em termos de uso da violência directa. As velhas guerras seriam motivadas por ideologias de mudança social, bem definidas, claramente articuladas, universalistas, enquanto que as novas guerras tenderiam a ser motivadas por preocupações que vão pouco além do mero ganho privado, variando apenas entre ganância (greed) e ressentimento (grievancé) (Collier e Hoeffler, 2000). São as "guerras sobre coisa nenhuma" a que se refere Enzensberger. E, por ser assim, a uma suposta violência controlada das velhas guerras teria sucedido uma violência gratuita nas novas guerras. Kalyvas mostra, porém, que a ideia de que as guerras civis são gratuitamente cruéis é anterior à emergência das chamadas novas guerras civis: "a violência dos mais fortes pode expressar-se através do uso de explosivos ou bombas de napalm. Mas estas armas não são diferentes das granadas de mão atiradas do cimo de telhados" (2001: 115). Por outro lado, a falta de sentido da violência das novas guerras civis não é tão gratuita como aparenta: é estratégica. Assim, por exemplo, as atrocidades cometidas na Serra Leoa (1998-1999), na Bosnia (1992) ou no Congo (1997-2000) foram cuidadosamente planeadas e centralizadas, resultantes de uma estratégia orquestrada para aterrorizar as vítimas, apoiadas e controladas a partir do exterior.

Em suma, há muito de construído nesta visão que opõe velhas a novas guerras civis. Pode dizer-se que o destaque dado às notas da despolitização e da criminalização das guerras civis mais recentes é não tanto expressão de uma novidade empírica mas antes resultado da falta de categorias conceptuais adequadas, isto é, de se tratar de conflitos que não se ajustam a uma determinada concepção de guerra.

Estes espaços ou zonas de indefinição não são, contudo, recentes. Ao longo do século XX (em particular na segunda metade do século), ao mesmo tempo que se proclamava a extinção de guerras assumidas como tal, em particular na Europa, eclodiram conflitos nos quais morreram mais pessoas do que na II Guerra Mundial. No entanto, como estas guerras não se ajustavam a uma determinada concepção de guerra, foram vistas como periféricas, marginais, "conflitos de baixa intensidade", guerras irregulares e informais. 
As novas características da violência fazem de facto com que as diferenças entre as zonas de combate e as zonas de paz aparente não sejam tão claras como em épocas anteriores e que, neste novo cenário, "[AJssim como é difícil distinguir entre o político e o económico, o público e o privado, o militar e o civil, [seja] também cada vez mais difícil distinguir entre a guerra e a paz" (Kaldor, 2001:143). As condições da guerra e da paz tomaram-se, neste sentido, relativas, não são (mais) absolutas ou opostas. A proliferação de armas ligeiras, os níveis de violência, morte e deslocamento aproximam as zonas de paz e de guerra. A paz tomou-se numa condição relativa, revelando a persistência de economias políticas violentas. Nas palavras de Duffield, muitas das guerras dos anos 90 surgem como uma amplificação das relações internas e contradições que moldaram a paz formal de períodos anteriores que, afinal, já correspondia a uma paz violenta, ou a uma zona de indefinição (2001: 188-189).

Temos vindo a assistir, portanto, a uma tendência para a materialização de uma nova geografia da violência organizada, a uma escala cada vez mais micro, com guerras locais em rede (Duffield, 2001). Mas é porventura mais do que apenas uma nova geografia: é uma nova identidade da guerra como exacerbação das violências.

\subsection{Novíssimas formas e contextos de violências?}

A guerra deixou de ser, portanto, um momento isolado de intensa irracionalidade e violência, com um começo e um fim claros, para se transmutar em expressão constante de uma cultura de violência, embora com uma intensidade e uma radicalidade inconstantes. Estaremos a presenciar a criação de novas, ou de novíssimas zonas de indefinição ou zonas de paz violenta, que se alimentam e ao mesmo tempo possibilitam a perpetuação da economia política das guerras contemporâneas? Estarão a emergir novíssimas guerras nas entrelinhas, nas brechas das novas guerras? As guerras irregulares e informais da segunda metade do século XX foram o prelúdio das novas guerras dos anos 90, que na opinião de Kaldor têm ainda objectivos políticos - por reivindicarem o poder estatal e que passam ainda pela reclamação de poder com base em identidades (2001:69). Estará a emergir actualmente um novo tipo de violência que, por não corresponder (ainda) a nenhum daqueles requisitos, é por isso tido como irrelevante no estudo das guerras "a sério"? (Moura, 2005)

As novas guerras diferem da paz violenta em termos de escala ou grau, mais do que em condições absolutas ou opostas: a existência de um conflito armado declarado pressupõe a existência de nichos de autoridade com poder suficiente para mobilizar redes transnacionais necessárias para sustentar essa 
violência (Duffield, 2000:190). A dinâmica de disseminação física da violência organizada e armada, a uma escala cada vez mais micro - e, contudo, globalizada está bem patente sobretudo nas zonas de indefinição, onde a guerra se confunde com a paz. E mesmo em contextos de paz institucionalizada - seja em sociedades que atravessam um período de reconstrução pós-bélica, seja em sociedades saídas de regimes autoritários que vivem um período de transição democrática - se identificam os "nichos de autoridade com poder suficiente para mobilizar redes transnacionais" que permitem a perpetuação das novas guerras, por um lado, mas que, e acima de tudo, contribuem para a reconfiguração de um novo tipo de violência, a que chamamos novíssimas guerras, com actores, condutas e objectivos que são simultaneamente comuns e distintos das novas guerras.

Em sociedades que vivem processos de reconstrução pós-conflito dominados por preocupações de curto prazo e por um quadro de referências políticas, económicas e sociais de recorte neo-liberal, facilmente se opera uma transferência da violência militar anterior para uma violência social disseminada, em que o arsenal de cultura de violência acumulada ao longo de décadas jorra em violência armada organizada, ao mesmo tempo que radicaliza expressões de violência cultural e se exprime em violência estrutural não dissimulada. Em países saídos de regimes autoritários, a reforma policial e do sistema judicial não foi bem sucedida, ou nem sequer ocorreu. Não houve, deste modo, um desmantelamento de estruturais institucionais de opressão do passado e, perante a ausência de meios institucionais de resolução democrática de conflitos por parte do Estado, assistimos à perpetuação de antigos medos e inseguranças, numa era a que Winton (2004) chama "violência pós-autoritária".

Por outro lado, e mesmo fora destes contextos identificados de reconstrução pós-bélica, registam-se situações de hiper-concentração territorial de violência armada (organizada) em contextos mais vastos de paz institucionalizada e formal. Kaldor (2000) afirma que as condições que deram origem às novas guerras e que são exacerbadas por elas existem em formas maisfracas na maioria dos aglomerados urbanos do mundo, que muitas vezes têm ligações directas com regiões mais violentas. Para essa mesma tendência de "urbanização dos conflitos" aponta Dufour (1997: 41), para quem "as cidades serão os campos de batalha do próximo século".

De facto, nesta reconfiguração das manifestações e tipologías da violência, os espaços urbanos e as suas periferias são os territórios eleitos das novíssimas guerras. Como observa Eduardo Galeano, relativamente à Nicarágua, a paz reinava nas ruas das cidades do país durante os anos da guerra; mas, desde que a paz foi declarada, as ruas tomaram-se cenários de guerra, campos de batalha (Galeano, 1998: 314-316). Esta profunda crise social das cidades - que resulta de e tem 
como consequência o aumento de urna nova tipología da violência tem conduzido à emergência de novos rótulos como os de "cidade falhada", "novas selvas urbanas" ou "urbicídio" (Shaw, 2000). Briceño-León e Zubillaga (2002) salientam, por exemplo, que a taxa de homicídios é substancialmente superior nos bairros pobres e periféricos do Rio de Janeiro, quando comparada com as taxas registadas nas áreas habitadas pela classe média - 177,59 e 38 por 100 mil habitantes, respectivamente. Ou seja, a "democratização da violência" é imperfeita, e alguns sectores e espaços da sociedade e da cidade são mais vulneráveis à violência do que outros. Assistimos, portanto, desde há uns anos, a uma reconfiguração dos próprios conflitos urbanos. As revoltas pontuais de cidadania, com objectivos limitados, testemunhadas pelas grandes cidades dos países ricos (Young, 1999), transformam-se em guerras civis, permanente e militarmente organizadas, em espaços urbanos com maiores desigualdades sociais.

Neste contexto, a nossa hipótese é a de que neste novíssimo tipo de conflitualidade se cruzam duas dinâmicas de sentido oposto: de um lado, uma dinâmica "descendente" traduzida numa "descida" da violência armada cada vez mais ao terreno do doméstico; do outro, uma dinâmica "ascendente" que se concretiza na intensificação de formas ditas "tradicionais" de violência (sub)urbana. A perda de nitidez da fronteira entre as esferas interna e internacional em cenários de novíssimas guerras faz com que a definição ou caracterização desta nova conflitualidade dependa das "lentes" ou dos filtros com que analisamos estes contextos. Se nos centrarmos única e exclusivamente na dimensão intema, pouco mais veremos do que um cenário de criminalidade hiper-concentrada, sem objectivos políticos. Mas se compreendermos as articulações entre estes fenómenos locais e o contexto internacional, veremos que estamos perante a emergência de conflitos de tipo novo, disseminados à escala global. Sendo conflitos que se tomaram mais visíveis dentro dos limites de um bairro ou de uma favela, as novíssimas guerras são hiper-locais. Mas a sua disseminação e a articulação densa e concreta de muitas das suas dimensões tomam-nas num fenómeno global.

A globalização é democrática e igualitária na disseminação de expectativas, mas é desigual na oferta de meios que as satisfaçam (Briceño-Leon e Zubillaga, 2002:28). Nesse contexto de perda do significado da cidadania e de descrédito do sistema de segurança nacional, as opções de escolha para os jovens de centros urbanos tomam-se limitadas. A crescente fragmentação social e polarização resultantes destes cenários são compensadas, em alguns casos, com o desenvolvimento de formas de identidade social alternativas e a busca de poder económico e simbólico (Winton, 2004: 175). Neste contexto, emergem gangs ou facções armadas, actores privilegiados destas novíssimas guerras, intimamente relacionados com o narcotráfico e o tráfico de armas. De facto, o equilíbrio entre as motivações 
económicas e sociais de membros de gangs em alguns contextos pende para o lado económico, e os gangs estão cada vez mais relacionados com, e muitas vezes transformados em, grupos criminosos organizados (Kinnes, 2000; Dowdney, 2003).

\subsection{Masculinidade e sistema de guerra: da casa ao mundo}

Se há algo de desafiante no itinerário velhas-novas-novíssimas guerras é o questionamento da separação analítica entre guerra e "formas menores" de violência. Esse itinerário mostra precisamente o acerto da noção de continuuns de violências como expressão de uma realidade em que a guerra não é um facto social isolado mas antes algo que impregna, como sistema cultural, o nosso quotidiano.

Para B.Reardon (1985) o sistema patriarcal é, em si mesmo, um sistema de guerra cujos aspectos violentos marcam profundamente as nossas vidas em todas as escalas. A invenção e institucionalização da guerra representam um instrumento específico deste sistema de guerra, destinado a perpetuar a ordem social que ele criou. Trata-se, de facto, de um sistema que se traduz numa ordem social competitiva, baseada em princípios autoritários, que pressupõe um valor desigual entre seres humanos, que é colocada em prática através da coerção, que institucionaliza a dominação masculina em estruturas verticais, e que é legitimada pela cultura (Reardon, 1985:10;Galtung, 1996:40). Existe uma pequena minoria, uma elite, que controla a maioria através do medo e da insegurança, privilegiando uma noção de segurança que legitima o uso da força ao nível intemo e extemo, promovendo o militarismo e a militarização das sociedades. $\mathrm{Na}$ verdade, a militarização das sociedades tem um alcance cultural e não exclusivamente político e desenvolve-se não só em períodos de guerra mas também em tempos de paz: a militarização não corresponde ao simples acto de ingressar no exército ou de possuir e utilizar uma arma. Trata-se de um processo bastante mais subtil, que atravessa e influencia toda a rotina diária, enraizado na ideologia, nas instituições ou na economia, chegando a ser considerado algo de normal ou mesmo nobre (Enloe, 2000).

Podemos então afirmar que a exacerbação da masculinidade hegemónica e militarizada é o fundo comum que une as culturas de violência presentes em todas as escalas de guerra - as "velhas", as "novas" e as "novíssimas"? E que, à medida que a tipología da conflitualidade se transforma, são desafiados e questionados os mitos e estereótipos que subjazem à legitimação do sistema de guerra? Se a guerra reforça um modelo hegemónico de masculinidade, que por sua vez reforça a guerra (Dolan, 2002: 60), como interpretar a reconfiguração 
da conflitualidade internacional - dos seus actores, condutas, motivações que temos vindo a testemunhar desde o final da Guerra Fría? Será a emergência de "novas" guerras - e mais ainda, de "novíssimas" guerras - sinónimo de uma crise da masculinidade ou da desmasculinização do cidadão-guerreiro, protector, racional, utilizado e manipulado enquanto forma de legitimação das guerras tradicionais? Se assim for, podemos afirmar que a nova geografia das violências corresponde à própria desmasculinização da guerra?

Há aparentemente razões para pensar assim. A masculinidade que esteve subjacente à criação e manutenção de exércitos nacionais, que participava nas guerras sacrificando-se pela nação, que (supostamente) protegia os mais débeis, as desprotegidas, que através do serviço militar era detentora de cidadania plena, atravessa um período de crise. Precisamente porque foi construída com o objectivo de legitimar um determinado tipo de guerra que tem vindo a desaparecer.

Os desafios ou questionamentos à masculinidade hegemónica evidenciam-se, desde logo, na desmasculinização como estratégia declarada de humilhação do inimigo (Turshen e Twagiramariya, 1998: 10). A violência sexual sistemática constitui uma arma e um objectivo de guerra, especialmente em conflitos étnicos. A violação é utilizada como acto de humilhação contra as mulheres e contra os homens seus familiares e das suas comunidades. A estratégia segue a mesma lógica, a de desumanizar, humilhar e, acima de tudo, desmasculinizar o grupo de protectores que não se consegue proteger a si mesmo ou aos seus desprotegidos(as). Por outro lado, a entrada das mulheres nas forças armadas e a reconfiguração das funções dos exércitos, do combate para a manutenção da paz (Van Creveld, 2000:437), dão conta de uma redefinição dos papéis sociais associados ao corpo militar. Enfim, a estratégia de "baixas zero" parece traduzir uma abdicação de um modelo de masculinidade apontado à exaltação do sacrifício e da plena disponibilidade física.

Em suma, este é claramente um tempo de mudança dos padrões tradicionais de articulação entre masculinidade e guerra. Todavia, mudando os padrões mantém-se a articulação essencial entre formas dominantes de masculilnidade e guerra, como fundamento cultural de práticas violentas. E sempre, insistimos, segundo uma lógica de continuum.

Coexistem, actualmente, perante a emergência de novas e novíssimas guerras, vários tipos de masculinidades que tentam legitimar vários tipos de guerras e que se transformam com o objectivo de manter a sua hegemonia. No entanto, a emergência de novos e novíssimos tipos de guerra é possível porque o sistema que lhes subjaz tem uma enorme capacidade de transformação e adaptação. As velhas masculinidades hegemónicas, que permitiram e resultaram das guerras tradicionais com motivações ideológicas, enfrentam actualmente uma crise de 
hegemonia, um desafio às razões da sua existência e manutenção, mais do que um processo de desmasculinização. No entanto, negoceiam-se as identidades necessárias à legitimação e perpetuação das novas e novíssimas guerras.

Se assim for, as identidades subjacentes a e perpetuadas pelos novos e novíssimos sistemas de guerra apresentam necessariamente novas características. Os objectivos políticos, de cariz ideológico, foram substituídos por objectivos económicos e por políticas de identidade; os Estados deixaram de ser os principais actores das guerras contemporâneas e em seu lugar emergem grupos armados informais; a escala da conflitualidade é cada vez mais local, apesar de globalizada, e afecta cada vez mais a população civil; as armas pesadas foram substituídas por armas ligeiras, fazendo com que se tome ténue a divisão entre zonas de guerra e zonas de paz. Neste horizonte de mudança tão acentuada, o elenco de valores tidos como centrais na construção de uma masculinidade dominante que naturaliza as violências atravessa uma zona de turbulência. Passageira como todas as turbulências?

\section{Referências bibliográficas}

BIGO, D. (1996) - "Guerres, conflits, transnational et territoire”, Guerres et Conflits, 21/22.

BOUTHOUL, G. (1976) - Le défi de la guerre. Paris: P.U.F.

BRICEÑO-LEÓN, R. e Zubillaga, V. (2002) - "Violence and globalization in Latin America", Current Sociology 50 (1).

DAVID, P. C. (2001)-A guerra e a paz. Abordagens contemporâneas da segurança e da estratégia. Lisboa: Instituto Piaget.

DOLAN, C. (2002) - "Collapsing masculinities and weak States - a case study of Northern Uganda", in CLEAVER, F. (ed.) (2002) - Masculinities Matter! Men, Gender and Development. London: Zed Books.

DUFFIELD, M. (2001) - Global Govemance and theNew Wars. Londres: Zed Books. COLLIER, P. e HOEFFLER, A. (2000) - "Greed and grievance in civil war", World Bank Policy Research Paper 2355, Washington D.C., World Bank.

DOWDNEY, L. (2003) - Crianças do tráfico: um estudo de caso de crianças em violência armada organizada no Rio de Janeiro. Rio de Janeiro: 7 Letras.

DUFOUR, J. L. (1997) - “La guerre survivra-t-elle au XXI sciècle?”, Politique Etrangère, 62.

ENLOE, C. (2000) - Maneuvres: the internationalpolitics of militarizing women 's lives. Berkeley/Los Angeles: University of California Press.

GALEANO, E. (1998) - Patas arriba. La escuela del mundo al revés. Madrid: Siglo Veintiuno. 
GALTUNG, J. (1969) - "Violence, peace and peace research", Journal ofPeace Research, 6(3).

GALTUNG, J. ( 1990) - "Cultural violence”, Journal of Peace Research, 27(3).

GHEBALI, V. Y. (2001) - "Les guerres civiles de la post-bipolarité: nouveaux acteurs et nouveaux objectifs", Relations Internationales, 105.

HERRMANN, I. e PALMIER!, D. (2003) - "Les nouveaux conflits: une modernité archaïque ?", Revue Internationale de la Croix Rouge, 85 (849).

HOLSTI, K. (1996) - The state, the war and the state of war. Cambridge: Cambridge University Press.

KALDOR, M. (2000) - "Cosmopolitanism and organised violence", Conceiving Cosmopolitanism Conférence, Warwick, 27-29 abril 2000.

KALDOR, M. (2001) - New and old wars. Organized armed violence in a global era, S. Francisco: Stanford University Press.

KALYVAS, S. N. (2001) - “'New' and 'old' civil wars: a valid distinction?", World Politics, 54 (1).

KINNES, I. (2000) - "From urban Street gangs to criminal empires: the changing face of gangs in the Western Cape", ISS Monograph Series 48, Institute for Security Studies, Pretoria, http://www.iss.org.za/Pubs/Monographs/No48/ Contents.html.

MANDELBAUM, M. (1999) - "Is major war obsolete?", Survival, 40.

MOURA, T. (2005) - "Novíssimas guerras, novíssimas pazes. Desafios conceptuais e políticos", Revista Critica de Ciências Sociais, 71.

NEP (2002) - "Failed and collapsed States in the international System. A report prepared by the African Studies Centre (Leiden), the Transnational Institute (Amsterdam), the Peace Studies Group (Coimbra) and the Peace Research Centre (Madrid)", $\quad$ http://www.ces.uc.pt/nucleos/nep/documentos/ failed_collapsedStates-Report.pdf.

REARDON, B. (1985) - Sexism and the war System. New York: Teachers College Press.

ROMEVA i RUEDA, R. (2003) - Guerra, posguerra y paz. Barcelona: Icaria Editorial. ROTBERG, R. I. (2003) - When States fail: causes and conséquences. Princeton: Princeton University Press.

SMITH, D. (2001) - "The problem of essencialism” in SKJELSBAEK, I. e SMITH, D. (eds.) - Gender, Peace \& Conflict. London: Sage Publications.

SHAW, M. (2000) - "New wars of the city: 'urbicide' and 'génocide", http:// www. martinshaw. org/city. htm.

TORTOSA, J. M. (2003) - Violencias ocultadas. Quito: Editorial Abya-Yala.

TURSHEN, M. e TWAGIRAMARIYA, C. (eds.) (1998) - What women do in wartime. Gender and conflict in Africa. London: Zed Books.

VAN CREVELD, M. (1991) - The transformation ofwar. New York: Free Press. 
VAN CREVELD, M. (2000) - "The great illusion: women in the military", Millennium: Journal of International Studies, 29 (2).

WALLENSTEEN, P. e SOLLENBERG, M. (2001) - “Armed conflict, 1989-2000”, Identijying wars: systematic conflict research and its utility in conflict resolution and prévention conférence. Uppsala: PRIO/Uppsala University.

WINTON, A. (2004) - "Urban violence: a guide to the literature", Environment\& Urbanization, 16 (2).

WRIGHT, Q. (1942) - Study of war. Chicago: University of Chicago Press.

YOUNG, J. (1999) - The exclusive society. London: Sage Publications.

ZARTMAN, I. W. ( 1995) - Collpased States. The désintégration and restoration of States. Boulder: Lynne Rienner. 